\title{
A GESTÃO SOCIAL NO CONTEXTO DA GESTÃO AMBIENTAL: ANÁLISE DA CRIAÇÃO E OPERACIONALIZAÇÃO DO PROJETO 3R ARQ-UFSC
}

\author{
Adriana Regina Costa Espíndola \\ Mestre em Administração Universitária \\ Universidade Federal de Santa Catarina - UFSC \\ centroanand@gmail.com \\ Luis Moretto Neto \\ Doutor em Engenharia de Produção \\ Centro Universitário Internacional - UNINTER \\ luis.morettoneto@ufsc.br \\ Victor Burigo Souza \\ Mestre em Administração \\ Universidade do Estado de Santa Catarina - UDESC \\ Centro de Educação Superior da Foz do Itajaí - CESFI \\ victorburigosouza@gmail.com
}

\begin{abstract}
RESUMO
A crise socioambiental enfrentada pela sociedade contemporânea aponta para a necessidade permanente de se pensar alternativas para o desenvolvimento da vida em sociedade. A gestão social tem se apresentado como alternativa na área da administração pública, onde a participação de cidadãos na produção do bem comum é uma prerrogativa dos processos de participação deliberativa, e que pode levar à emancipação. Esta pesquisa, realizada por meio de um estudo de caso qualitativo, teve o objetivo de analisar o processo de criação e de operacionalização do projeto 3R (Redução, Reuso e Reciclagem) do ARQ-UFSC (Departamento de Arquitetura e Urbanismo da Universidade Federal de Santa Catarina) à luz dos pressupostos conceituais que fundamentam a gestão social no contexto da gestão ambiental. A aludida pesquisa teve como base a implantação de uma cultura diferenciada para a gestão de resíduos sólidos no âmbito do Departamento de Arquitetura e Urbanismo do Centro Tecnológico da Universidade Federal de Santa Catarina. A análise dos dados indicou que a ideia da interdisciplinaridade que envolveu a criação do projeto aliada a prática participativa, operacionalizou aspectos da abordagem teórica da gestão social.
\end{abstract}

Palavras-chave: Administração pública; Gestão ambiental; Gestão social; Universidade.

\section{THE SOCIAL MANAGEMENT IN THE CONTEXT OF ENVIRONMENTAL MANAGEMENT: analysis of creation and operation of the project 3R ARQ-UFSC}

\begin{abstract}
The social-environmental crisis faced by the contemporary society points to the urgent need to think of alternatives for life development in the society. The social management emerged as an alternative in the public administration area, where the participation of citizens as subjects' citizens in the production of the common good is a prerogative within deliberative participation processes, and that can lead to emancipation. This research, carried out through a qualitative case study aimed to analyze the process of creation and operation of the project 3R (Reduce, Reuse and Recycle) of ARQ-Ufsc (Department of Architecture and Urbanism of the Federal University of Santa Catarina) in the light of the conceptual assumptions underlying social management in the context of environmental management. The aforementioned project is scoped to the implementation of a different culture for solid waste management under the Department of Architecture and Urbanism of the Technology Center of the Federal University of Santa Catarina. Data analysis indicated that the idea of interdisciplinary, which involved the creation of the project, combined with participatory practice operationalized aspects of the theoretical approach to social management.
\end{abstract}

Key words: Environmental management; Public administration; Social management; University. 


\section{INTRODUÇÃO}

A administração pública passa por um momento singular, pois ela também reflete, sob diversos ângulos, as transformações que vêm ocorrendo na sociedade e no planeta. No passado, a administração pública se preocupava apenas com questões relacionadas a produção, eficiência e eficácia dos serviços públicos. Entretanto, desde a segunda metade do século XX, o campo da administração vem se preocupando com questões relacionadas a participação, a emancipação humana, ao bem comum e, por consequência, ao meio ambiente. Como reflexo, os estudos acerca da gestão social e da gestão ambiental vêm se intensificando nas arenas de debate acadêmico.

O contexto de problemas sociais, econômicos e ambientais, somados a iniciativas internacionais (Meadows, Meadows \& Randers, 1972), fizeram com que diversos países elaborassem ações voltadas a estes temas. Políticas e legislações de proteção ao meio ambiente foram elaboradas para conter os problemas criados, principalmente, pela expansão do sistema de mercado. Foi nesse contexto que o Projeto 3Rs - Reduzir, Reutilizar e Reciclar - criado em 2006 pelo Departamento de Arquitetura e Urbanismo - ARQ - da Universidade Federal de Santa Catarina - UFSC - busca trabalhar com a prevenção e não geração de resíduos sólidos, reduzindo a utilização de recursos naturais.

A Universidade Federal de Santa Catarina - UFSC, desde a década de 1990, tem estabelecido ações em resposta à emergência do tema ambiental. No entanto, o histórico de iniciativas institucionais tem se caracterizado pelo padrão de gestão top down, a qual, sem entrar no mérito das diversas dificuldades inerentes à sua complexa constituição, pode ser tomada como exemplo de certo nível de alienação. Dessa forma, o corpo social, formado por servidores docentes, discentes e técnicos da UFSC, em sua maioria, encontra-se na condição de espectador de um cenário amplamente divulgado e discutido acerca de valores e ações necessários para alcançar o desenvolvimento socioambiental.

O tema principal desta pesquisa se insere, nesse contexto, relacionado a universidade, a gestão social e ambiental, pois ele trata da análise do projeto de gestão ambiental 3R do ARQUFSC com base em pressupostos da gestão social. Ainda de acordo com esse tema, o foco específico da pesquisa é analisar as ações implementadas pelo projeto sob a ótica do processo de discussão, do pluralismo e do bem comum, além de apresentar sugestões para a gestão de resíduos sólidos na UFSC.

A gestão social possui em seu escopo teórico diferentes características. Dentre essas características, é possível mencionar o interesse bem compreendido, o conceito de esfera pública, a ação racional substantiva, a emancipação humana e a cidadania deliberativa (Cançado, Pereira \& Tenório, 2015). Essa última corresponde a tomada de decisão, orientada pelos princípios do processo de discussão, inclusão, pluralismo, igualdade participativa, autonomia e bem comum. Transformados em categorias de análise (Villela, 2012), os princípios do processo de discussão, pluralismo e bem comum foram utilizados como base para o estudo do tema.

Esse estudo se justifica pela necessidade de ampliar o entendimento de uma adequada gestão ambiental no âmbito institucional da UFSC. Nesse contexto, a gestão social, com a sua abordagem teórica e princípios que preconizam a emancipação do ser humano, como cidadão, a diversidade de ideias e de atores, pode servir de base para esse entendimento. Essa linha de pensamento traz, em seu bojo, a possibilidade de mudanças na base de formação da sociedade que, contemporaneamente, tem apresentado uma enorme gama de desequilíbrios socioambientais, replicados por toda a sociedade. Para o campo da gestão ambiental, de forma diferenciada, pressupostos da gestão social, como a emancipação e autonomia, trazem a expectativa da atuação direta de cidadãos na idealização e implementação de ações, o que pode contribuir para a construção ou para o resgate de valores impulsionadores de mudanças no comportamento da vida do homem em sociedade e de suas relações com a natureza.

Devido a essa lacuna, a pesquisa tem como objetivo analisar o processo de criação e de operacionalização do projeto 3R (Redução, Reuso e Reciclagem) do ARQ-UFSC (Departamento de 
Arquitetura e Urbanismo da Universidade Federal de Santa Catarina) à luz dos pressupostos conceituais que fundamentam a gestão social no contexto da gestão ambiental.

Com foco nesse objetivo, essa pesquisa, após essa (1) introdução, apresenta o (2) referencial teórico que dá suporte ao desenvolvimento da pesquisa; e (3) os procedimentos metodológicos. Na sequência, é exposta a (4) apresentação e discussão dos resultados da pesquisa, as (5) considerações finais e as referências utilizadas.

Presentes o objetivo e a estrutura desta pesquisa, e, na ausência de maiores investigações empíricas que estudam a gestão social no contexto da gestão ambiental numa universidade pública, realiza-se uma apropriação de princípios da cidadania deliberativa para a coleta e análise dos dados. Com base nesses princípios, transformados em categorias de análise, são descritas algumas ações implementadas pelo projeto 3R do ARQ-UFSC e, posteriormente, analisadas sob a ótica da gestão social. Com fundamento nesta análise, são apresentadas sugestões para a gestão do projeto.

\section{REFERENCIAL TEÓRICO}

Para alcançar o objetivo que essa pesquisa se propõe, é necessário um arcabouço teórico que demonstre as principais características da universidade e as características que a diferenciam das demais instituições. É imperativo, também, que o referencial teórico levante as principais características da gestão social e da gestão ambiental, para que seja possível analisar o processo de criação e operacionalização do projeto 3R ARQ-Ufsc. Esses assuntos serão apresentados a seguir.

\subsection{Universidade: crises e oportunidades}

A universidade foi pensada como uma estratégia de ação social, fundada no reconhecimento público de suas atribuições. Segundo Chauí (2003), esse aspecto a diferencia e lhe confere autonomia perante outras instituições sociais. Para essa autora, a legitimidade da universidade moderna se deu em razão da ideia de um conhecimento guiado por necessidades imanentes, inseparáveis a ele, o que pode significar que há possibilidades da universidade gerar o conhecimento necessário para atender às diversas necessidades da sociedade, visando a transformação social requerida. Logo, a crise socioambiental, vista nas desigualdades sociais e na degradação ambiental, requer que o conhecimento almejado por pesquisadores seja inseparável das necessidades visíveis e vizinhas à universidade.

À vista disso, há atribuições e características que diferenciam a universidade de outras instituições sociais. A diferença da atuação de uma universidade pública em relação às demais instituições de ensino está, justamente, em usufruir de sua autonomia intelectual, relacionando-se de forma complexa com o Estado e com o todo da sociedade. Essa singularidade pode oportunizar um ambiente para a reflexão crítica, devolvendo à sociedade civil mentes pensantes que poderão dar bases às necessárias mudanças.

Estes posicionamentos seguem na linha do pensamento de Santos (2011), o qual entende que a universidade deve se voltar a atender às necessidades da sociedade. $O$ trabalho da universidade num formato institucional é árduo perante a sua responsabilidade social, para oferecer outros caminhos para a sociedade, atendendo ao que Morin (2010) chama de ter acesso à humanidade.

Tais observações reforçam a importância do papel da universidade na formação de autênticos cidadãos críticos, reflexivos, sujeitos de seu projeto histórico, que, dessa maneira, por sua vez, poderão, com autonomia, gerar novos conhecimentos. Quando a universidade cumpre esse papel, ela está alcançando sua função de dotar o ser humano para que o mesmo trabalhe e realize suas capacidades individuais (Steiner, 2011). Essas capacidades individuais são fundamentais para a autorrealização e atualização humana (Ramos, 1981).

Com relação as formas de trabalho e de desenvolvimento de pessoas, é pertinente considerar o pensamento de Sachs (1986). Este autor, menciona que o ecodesenvolvimento é uma construção direcionada para a ação, com ênfase em decisões que espelhem a realidade local, com a participação 
da comunidade. Dessa forma, podem ser encontrados caminhos alternativos para novos padrões de comportamento, também, na universidade. A caracterização da universidade, nos moldes de uma instituição social, se coaduna com a definição de ser público proposta por Habermas (2003). Para esse autor, o atributo de público está relacionado à tarefa de promover o bem público e o bem comum à todos os cidadãos.

A importância destas reflexões pode, ainda, ser visualizada na área ambiental. Ocorre que o potencial da universidade, em suas áreas de atuação do ensino, da pesquisa e da extensão, pode abrir possibilidades para mudanças de comportamento da sociedade e de suas relações com os recursos naturais.

\subsection{Gestão social: a construção de sua abordagem teórica conceitual}

Na área da administração pública, as mudanças necessárias para a melhoria da qualidade de vida, para a busca de equidade e de justiça social, têm levado pesquisadores a repensar o modo de administrar. Esse processo é movido, também, pelo esgotamento das teorias organizacionais tradicionais que já não atendem mais as necessidades da sociedade, resultando na busca por alternativas na área da administração (Cançado, Pereira \& Tenório, 2015). O Estado como interlocutor, mediador e mesmo promotor do desenvolvimento da sociedade, no âmbito do espaço público, da esfera pública, caracteriza-se, de acordo com Tenório et al. (2008), pela busca de soluções por meio da concordância dos diferentes atores partícipes do processo decisório.

O termo gestão social passou a fazer parte da linguagem acadêmica no início da década de 1990. Desde então, a gestão social se apresenta como um campo emergente que pode ser observada em pelo menos quatro linhas centrais de abordagens (Peres Jr. \& Pereira, 2014). A primeira linha é uma abordagem crítica frankfurteana, como os trabalhos de Cançado, Pereira \& Tenório (2015) e Villela (2012), compreendendo a gestão social como um processo dialético de organização social próprio da esfera pública, alicerçado no interesse bem compreendido e na emancipação humana. A segunda linha pode ser observada no trabalho de Fischer (2012), que compreende a gestão social como a gestão do desenvolvimento territorial e social por meio da noção de interorganizações. Os autores mencionam a existência de uma terceira linha de abordagem ancorada nas produções de Dowbor (1999) e Cabral (2006). Essa abordagem discute a gestão social, principalmente, com enfoque no terceiro setor e nos movimentos sociais, relacionados a área de serviço social. Por fim, há uma abordagem que trabalha a gestão social com base na participação do cidadão na administração pública, tendo como principal trabalho aquele de Paes de Paula (2005), que estabelece o concito de administração pública societal.

Assumindo cada uma dessas linhas, o processo de gestão passa a corresponder a demanda contemporânea por um futuro com maior participação cidadã na produção do bem comum. A compreensão dos efeitos da ação de gestão sobre um futuro dos serviços públicos participativos, modela a ação de gestão do presente, de acordo com Shommer e Boullosa (2011). O observadorgestor-social, definido por essas autoras, seria o mediador da dialogicidade, um dos pressupostos da gestão social, uma vez que o diálogo só existiria em sua função, e teria apenas fronteiras de aprendizagem, permitindo a abertura da dimensão social da gestão. Percebe-se, no significado desse entendimento, uma forma de gestão que prima por uma participação compartilhada baseada no pleno diálogo, buscando contrapor à forma tradicional de se pensar a Administração - ou a contemporânea gestão estratégica - onde a hegemonia estabelecida, ao contrário, preza pela competição e exclusão do outro.

Contribuindo para essa perspectiva de gestão social, Villela (2012) buscou elaborar critérios para a avaliação de processos decisórios participativos deliberativos. De acordo com o autor, o conceito de cidadania deliberativa está fundamentado em Habermas (1995) e relacionado com os critérios de avaliação da participação cidadã desenvolvidos pelo Instituto de Governo e Políticas Públicas da Universidade Autônoma de Barcelona (Igop) e com os critérios contidos nos trabalhos de Castellà \& Jorba (2005), Jorba, Martí \& Parés (2007), Parés \& Castellà (2008). Os autores 
tomaram como base a definição de cidadania deliberativa, onde as decisões políticas são legitimadas originalmente em processos de discussão, orientados pelos princípios do pluralismo, da igualdade participativa, da autonomia e do bem comum, e definiram critérios, categorias e indicadores como forma de avaliar os processos decisórios e deliberativos.

Para os fins dessa pesquisa, serão utilizadas as categorias: processo de discussão; pluralismo; e, bem comum (Villela, 2012). O processo de discussão está relacionado com a discussão de problemas, por meio da autoridade negociada na esfera pública, e pressupõe igualdade de direitos e é entendido como um espaço intersubjetivo e comunicativo que possibilita o entendimento dos atores sociais envolvidos. O mesmo autor aponta, como critérios para essa categoria os canais de difusão, a qualidade da informação, a existência de espaços transversais, a pluralidade do grupo promotor e a utilização de órgãos e estruturas já existentes. O pluralismo se refere a multiplicidade de atores (poder público, mercado e sociedade civil) que, a partir de seus diferentes pontos de vista, estão envolvidos no processo de tomada de decisão nas políticas públicas. Essa categoria possui como critérios a participação de diferentes atores no processo de decisão e as características desses atores, bem como suas experiências em processos democráticos. $\mathrm{O}$ bem comum diz respeito ao bem-estar social alcançado pela prática republicana. Os critérios para essa categoria são os objetivos alcançados e a aprovação cidadã dos resultados.

A síntese das categorias e dos indicadores, proposta por Villela (2012), para avaliar processos decisórios deliberativos, bem como o entendimento da importância da personalização histórica da pessoa, preconizada por Ramos (1996), esclarece e enfatiza quão importante é a participação cidadã no processo de construção de novas bases societárias. Isso permite a retomada das conquistas sociais e políticas retrocedidas em função de crises econômicas e da influência do neoliberalismo na regulação da vida social (Santos, 2011), por meio de diferentes atores e arranjos institucionais.

Tais possibilidades de rearranjos nas relações sociais e institucionais trazem luz ao tema deste estudo, que prima pelo diálogo entre a necessidade de pensar a gestão ambiental e os pressupostos da gestão social. Nesse âmbito, pode-se considerar o entendimento de Justen \& Neto (2012) acerca do que seria planejar na direção da implementação de novas bases para a sustentabilidade ambiental. Para esses autores, a noção de gestão social e ao paradigma da ecologia profunda estão circunscritos a um novo olhar crítico e reflexivo, dialógico e comunicativo, nas relações homem/homem, homem/organização, ambiente/organização e ambiente/homem. É com esta expectativa que as bases conceituais da gestão social podem contribuir para uma nova contextualização da gestão ambiental.

\subsection{Gestão ambiental: histórico e perspectivas de mudança}

À luz da literatura, a importância de se pensar em gestão ambiental remonta ao início da década de 1960 (Meadows, Meadows \& Randers, 1972). A preocupação tomou vulto, de fato, na medida em que se agravaram os problemas com o uso irracional da água em escala industrial e para o consumo humano (Carson, 1969). Também colaboraram para isso os problemas com a destinação inadequada do lixo, do uso excessivo do carro, da extração de recursos naturais e da poluição gerada em razão da produção de bens e serviços para o consumo. A problemática ambiental e a discussão acerca da influência do homem sobre a degradação do planeta, ganhou maior relevância ainda no final daquela década.

Já na década de setenta, os debates acerca do assunto começaram a se consolidar com a Conferência de Estocolmo, em 1972, sendo a primeira reunião das Nações Unidas sobre o meio ambiente. Sachs (2009) revela que esta conferência levantou uma alternativa média entre o economicismo arrogante e o fundamentalismo ecológico. Essa ideia se fundamenta num crescimento econômico socialmente receptivo e implementado por métodos favoráveis ao meio ambiente, em vez de favorecer a incorporação predatória do capital da natureza ao PIB. 
Desde então, outros eventos e encontros internacionais, como a Eco 92, o Protocolo de Quioto, a recente Rio + 20, além do Relatório Nosso Futuro Comum (1991), trouxeram a discussão acerca da gestão ambiental. Essas discussões invocaram a responsabilidade do indivíduo, da sociedade organizada e de Governos para a problemática resultante de atividades e ações do ser humano, e suas possíveis soluções.

Além desses aspectos históricos a respeito do debate relacionado a gestão ambiental, as perspectivas de mudança passam pela reflexão do atual paradigma que conduz a sociedade. Hirschman (2002) demonstra que o surgimento do capitalismo influenciou a substituição dos padrões da virtude humana pelos interesses enquanto forma de paixão mais branda. $\mathrm{O}$ autor demonstra que desde o século XVII o ser humano vem agindo com base em seus interesses pessoais, refletidos na busca incessante pelo crescimento econômico e acúmulo de riquezas. $\mathrm{O}$ paradigma condutor da sociedade, passou a ser o paradigma de mercado.

A ilimitada intrusão do sistema de mercado na vida humana tem demonstrado a incapacidade da teoria organizacional em oferecer diretrizes para a constituição de espaços onde indivíduos possam participar de relações sociais gratificantes, conforme menciona Ramos (1981). É um processo de mudança de padrão de comportamento, onde é de fundamental importância, o desenvolvimento de uma percepção acurada que leve o ser humano a reconhecer outras dimensões inerentes à sua natureza, o que pode resultar no discernimento e no senso de participação, nos moldes de possibilidades emergentes como a gestão social. Para Lievegoed (1994), além do subconsciente, o ser humano tem uma consciência superior, da qual pode retirar valores, normas e significados que podem revelar o futuro com certa finalidade. Se aproveitada, tal possibilidade pode provocar mudanças, fornecendo a força para orientar a psique para rumos não destrutivos.

O viver individualizado, o esperar pela ação do outro, o não envolvimento político na esfera pública, são padrões de comportamento que devem ser modificados. A abordagem teórica da gestão social, aparece como alternativa para a condução de tais mudanças. Para Dowbor (1999), essa alternativa seria de primeira importância em termos políticos e sociais, mas ainda requer que seus paradigmas sejam definidos. No processo de mudança é fundamental, portanto, encontrar formas de mobilização para propiciar o esclarecimento e, sobretudo, o desenvolvimento da capacidade de ser sujeito, assegurando uma participação cidadã (Tenório, 2008). O despertar para a capacidade de ser sujeito, perpassa a dimensão da individualidade adormecida e perene (Santos, 2011) e os pressupostos de Steiner (2011) quanto à inerente percepção subjetiva humana.

Nesses moldes, ao se pensar em alternativas para a gestão ambiental, é indispensável prezar pelos princípios da ecologia profunda abordada por Layrargues (1998), a partir de indivíduos autodesenvolvidos. Também é necessário considerar a racionalidade social, um dos pilares do ecodesenvolvimento definido por Sachs (1986) e por Leff (2001), e que seja fundamentada em processos calcados num modo de vida associativo, a partir do uso da razão substantiva apontada por Ramos (1981). Tais preceitos encontram ressonância na abordagem teórica da gestão social.

Essas relações entre a gestão social e a ambiental estão no centro deste estudo. Seu objetivo está vinculado a essa análise dos conceitos da gestão social no âmbito da gestão ambiental, justamente por se acreditar que tal conceituação pode abrir caminhos em diferentes direções na busca por alternativas ao sistema hegemônico que aí está, e que tem provocado grandes prejuízos ao planeta. Superada essa etapa teórica, serão apresentados, na sequência, os procedimentos metodológicos utilizados neste estudo.

\section{PROCEDIMENTOS METODOLÓGICOS}

Considerando o objetivo geral de analisar e diagnosticar ações identificadas na criação e gestão do Projeto 3R ARQ-UFSC, sob a ótica da gestão social, esta pesquisa foi realizada de acordo com as diretrizes de uma abordagem qualitativa. Godoy (2012) coloca que, quando o estudo é de caráter descritivo, com o objetivo de entender um fenômeno em sua complexidade e de procurar compreender a teia de relações sociais e culturais no interior de uma organização, a opção pela 
metodologia qualitativa pode ser a mais apropriada. Dessa forma, ao definir o objetivo central deste estudo, ou seja, a análise da criação e da operacionalização do fenômeno Projeto 3R à luz da abordagem teórica da gestão social, seguindo a orientação de Godoy, optou-se pelo formato qualitativo de estudá-lo.

Para realizar a articulação entre teoria e realidade empírica no formato do conhecimento científico, faz-se necessário um método que formule tal articulação (Minayo \& Sanches, 1993). Assim, para atingir o objetivo proposto e dar legitimidade científica à pesquisa realizada, estabeleceu-se uma metodologia de trabalho buscando contemplar todas as etapas, desde a busca de referenciais teóricos, passando pela coleta e análise de dados, até a obtenção dos resultados e conclusão do estudo. Para isso, foi delineado um plano de trabalho.

A primeira etapa foi uma revisão bibliográfica, exposta no referencial teórico e utilizada na análise dos resultados, sobre a temática da pesquisa, que, segundo Vergara (2010), oferece contextualização e consistência à investigação. Para contemplar esta etapa, buscou-se amparo em bibliografias nacionais e estrangeiras.

$\mathrm{Na}$ segunda etapa, foi realizado um estudo de caso do Projeto 3R. Foram realizadas coletas de dados em documentos, relatórios de atividades do Projeto 3R, entrevistas semiestruturadas, e na observação direta da pesquisa em campo. As entrevistas ocorreram por meio de uma amostra da população formada por servidores docentes e técnicos administrativos, alunos e apoiadores do Projeto, entre os anos de 2006 e 2012, totalizando 60 integrantes. Para objetivar a seleção dos sujeitos da amostra, foi realizado um agrupamento dos sujeitos, para condensar e obter uma representação simplificada dos dados brutos (Bardin, 1977). Seguindo esta orientação, delineou-se a participação dos integrantes da equipe de acordo com os seguintes grupos, expostos na figura 1: docentes, alunos e maquetaria, apoiadores internos, apoiadores externos e coordenação.

\begin{tabular}{|l|l|c|}
\hline \multicolumn{1}{|c|}{ Grupos } & \multicolumn{1}{|c|}{ Critério de Seleção } & Número de sujeitos \\
\hline Docentes: E3, E5. & $\begin{array}{l}\text { Integrantes do Grupo Interdisciplinar de Pesquisa } \\
\text { em Ecologia e Desenho (Gipedu) que fomentou o } \\
\text { Projeto 3R. Caracterizam a atuação interdisciplinar } \\
\text { do Projeto 3R. }\end{array}$ & 2 \\
\hline $\begin{array}{l}\text { Alunos e maquetaria: E1, E2, } \\
\text { E4, E6, E14, E15, E16 }\end{array}$ & $\begin{array}{l}\text { Grande envolvimento na execução do Projeto 3R. } \\
\text { Apontam para possibilidades de uma atuação } \\
\text { participativa em processos de discussão. }\end{array}$ & 7 \\
\hline $\begin{array}{l}\text { Apoiadores Internos à UFSC: } \\
\text { E7, E8, E9, E11, E13, E17 }\end{array}$ & $\begin{array}{l}\text { Apoio logístico e operacional. Acenam para a } \\
\text { participação intersubjetiva de atores de diferentes } \\
\text { instâncias da esfera institucional. }\end{array}$ & 6 \\
\hline $\begin{array}{l}\text { Apoiadores externos à UFSC: } \\
\text { E10, E18 }\end{array}$ & $\begin{array}{l}\text { Apoio operacional. Multiplicidade de atores } \\
\text { atuando em decisões no âmbito da esfera pública. }\end{array}$ & 2 \\
\hline Coordenação: E12 & $\begin{array}{l}\text { Responsabilização pela criação e execução do } \\
\text { Projeto 3R. }\end{array}$ & 1 \\
\hline & Total de sujeitos & 18 \\
\hline
\end{tabular}

Figura 1 - Grupos e critérios de seleção de sujeitos para compor a amostra

Fonte: Elaborado pelos autores

Além dos grupos que compõem a amostra deste trabalho, a figura 1, também, revela os critérios para a seleção dos sujeitos entrevistados. Ao final, a amostra ficou composta por 18 sujeitos, classificados de Entrevistado número um (E1) a Entrevistado número dezoito (E18).

De posse dos dados, foi realizada a terceira etapa desta pesquisa, referente a análise para a compreensão do processo de criação e de ações que suportaram o desenvolvimento do Projeto 3R, sob a ótica da gestão social. A consecução da análise dos dados quanto aos pressupostos da abordagem da gestão social foi feita com base em categorias de análise selecionadas, explicitadas na figura 2. 


\begin{tabular}{|c|c|c|}
\hline Categoria & Descrição da categoria & Critérios \\
\hline \multirow{8}{*}{$\begin{array}{l}\text { Processo de } \\
\text { discussão }\end{array}$} & \multirow{8}{*}{$\begin{array}{l}\text { Discussão de problemas por } \\
\text { meio da autoridade negociada } \\
\text { na esfera pública. Pressupõe } \\
\text { igualdade de direitos e é } \\
\text { entendido como um espaço } \\
\text { intersubjetivo e comunicativo } \\
\text { que possibilita o entendimento } \\
\text { dos atores sociais envolvidos. }\end{array}$} & $\begin{array}{l}\text { Canais de difusão: existência e utilização de canais } \\
\text { adequados ao acesso à informação para a mobilização dos } \\
\text { potenciais participantes. }\end{array}$ \\
\hline & & $\begin{array}{l}\text { Qualidade da informação: diversidade, clareza e } \\
\text { utilidade da informação proporcionada aos atores } \\
\text { envolvidos. }\end{array}$ \\
\hline & & $\begin{array}{l}\text { Espaços de transversalidade: espaços que atravessam } \\
\text { setores com o intuito de integrar diferentes pontos de vista. }\end{array}$ \\
\hline & & $\begin{array}{l}\text { Pluralidade do grupo promotor: compartilhamento da } \\
\text { liderança a fim de reunir diferentes potenciais atores. }\end{array}$ \\
\hline & & $\begin{array}{l}\text { Órgãos existentes: uso de órgãos e estruturas já existentes } \\
\text { evitando a duplicação das estruturas. }\end{array}$ \\
\hline & & $\begin{array}{l}\text { Órgãos de acompanhamento: existência de um órgão } \\
\text { que faça o acompanhamento de todo o processo, desde sua } \\
\text { elaboração até a implementação, garantindo a coerência e } \\
\text { fidelidade ao que foi deliberado de forma participativa. }\end{array}$ \\
\hline & & $\begin{array}{l}\text { Relação com outros processos participativos: interação } \\
\text { com outros sistemas participativos já existentes na região. }\end{array}$ \\
\hline & & $\begin{array}{l}\text { Abertura dos espaços de decisão: processos, } \\
\text { mecanismos, instituições que favorecem a articulação dos } \\
\text { interesses dos cidadãos ou dos grupos, dando uma chance } \\
\text { igual a todos de participação na tomada de decisão. }\end{array}$ \\
\hline \multirow[t]{2}{*}{ Pluralismo } & \multirow{2}{*}{$\begin{array}{l}\text { Multiplicidade de atores (poder } \\
\text { público, mercado e sociedade } \\
\text { civil) que, a partir de seus } \\
\text { diferentes pontos de vista, estão } \\
\text { envolvidos no processo de } \\
\text { tomada de decisão nas políticas } \\
\text { públicas. }\end{array}$} & $\begin{array}{l}\text { Participação de diferentes atores: atuação de } \\
\text { associações, movimentos e organizações, bem como } \\
\text { cidadãos não organizados, envolvidos no processo } \\
\text { deliberativo. }\end{array}$ \\
\hline & & $\begin{array}{l}\text { Perfil dos atores: características dos atores em relação as } \\
\text { suas experiências em processos democráticos de } \\
\text { participação. }\end{array}$ \\
\hline \multirow{2}{*}{ Bem comum } & \multirow{2}{*}{$\begin{array}{l}\text { Bem-estar social alcançado } \\
\text { através da prática republicana. }\end{array}$} & $\begin{array}{l}\text { Objetivos alcançados: relação entre os objetivos } \\
\text { planejados e os realizados. }\end{array}$ \\
\hline & & $\begin{array}{l}\text { Aprovação cidadã dos resultados: avaliação positiva dos } \\
\text { atores sobre os resultados alcançados. }\end{array}$ \\
\hline
\end{tabular}

Figura 2: Categorias e respectivos critérios selecionadas para a pesquisa

Fonte: Adaptado, pelos autores, a partir de Tenório et al. (2008)

A figura 2, utilizada para a análise dos dados, permite atingir o objetivo da pesquisa relacionando o entendimento obtido do referencial teórico com a realidade a ser encontrada na criação e gestão do Projeto 3R. Com esse foco, foram selecionadas as seguintes categorias: processo de discussão; pluralismo; e bem comum. A seleção foi feita com base na aderência destas categorias com objetivos e método de trabalho contemplados no Projeto 3R (UFSC, 2013).

O método utilizado para a análise dos dados coletados por meio das entrevistas semiestruturadas, com base nas categorias de análise selecionadas, pela análise documental e por observações diretas pelos pesquisadores, foi o de análise de conteúdo. De acordo com Bardin (1977), esse método viabiliza um tratamento da informação que proporciona uma análise do significado nela contido.

Conforme já colocado anteriormente, este estudo trata da análise do fenômeno de criação e de operacionalização do Projeto 3R, sob a ótica dos pressupostos conceituais da gestão social. Nas referências consultadas, a análise empírica/conceitual de experiências em gestão social tem sido abordada a partir de categorias explicitadas em critérios, o que viabiliza, e propicia clareza ao processo de avaliação e diagnóstico. Para Richardson (2007), as categorias são os conceitos básicos que refletem os aspectos essenciais, o que pode propiciar objetividade à análise do fenômeno. Expostos os procedimentos metodológicos, é possível apresentar e discutir os resultados da pesquisa. 


\section{APRESENTAÇÃO E DISCUSSÃO DOS RESULTADOS DA PESQUISA}

No decorrer da construção deste trabalho, de forma direta e indireta, informações e dados foram coletados, observações realizadas e percepções despertadas. De forma direta e programada, obtiveram-se os dados primários por meio das entrevistas semiestruturadas. De forma indireta, foram obtidas informações e percepções acumuladas por meio de contatos informais e de visitas a locais relacionados à gestão de resíduos sólidos gerados pela UFSC. Exemplo disso, foi o caso das idas ao pátio da Associação de Coletores de Materiais Recicláveis, no Bairro Itacorubi, município de Florianópolis, e ao pátio de compostagem do Centro de Ciências Biológicas - CCB, onde é realizada a reciclagem de resíduos orgânicos gerados no Campus da UFSC.

Dessa maneira, a análise aqui realizada é resultado de um processo e não apenas da correlação dos dados coletados com as categorias de análise previamente selecionadas. De igual modo, é efeito do amadurecimento de ideias e de visões dentro de um contexto de relações sociais e de trabalho, de posicionamentos individuais, de fatos e de problemas concretos no âmbito da gestão ambiental, notadamente na gestão de resíduos sólidos do Campus Trindade da UFSC, em Florianópolis.

O Projeto 3R foi iniciado em 2006 como parte integrante do conteúdo programático da disciplina de Planejamento Ambiental Urbano e de outras disciplinas do ARQ (Universidade Federal de Santa Catarina [UFSC], 2013). A sua operacionalização aconteceu por meio da participação de alunos na elaboração e execução de ações específicas, tais como diagnósticos, oficinas, construção de lixeiras, containers e outras ações necessárias à sua implementação.

Entre os anos de 2006 e 2011, segundo o relatório do UFSC (2013), foram realizadas ações para o diagnóstico da situação dos problemas gerados pela produção, pelo manuseio e pela destinação final dos resíduos sólidos no Campus Trindade da UFSC, além do levantamento das iniciativas em gestão de resíduos em diferentes setores da comunidade universitária. Então, foram implementadas iniciativas para dar início as mudanças na forma de tratar os resíduos sólidos produzidos no âmbito do ARQ. Uma das iniciativas ocasionou na realização de um levantamento da produção e do respectivo potencial de comercialização dos resíduos recicláveis do ARQ, com a participação da administração do Departamento e das funcionárias de limpeza. Outra ação que, de modo similar, agregou valor para uma mudança de comportamento, foi o reuso de materiais utilizados em maquetes, cuja produção e posterior descarte como lixo comum representava, além de danos ambientais, grande desperdício de materiais potencialmente reutilizáveis. Esse problema foi resolvido a partir da iniciativa do Projeto $3 \mathrm{R}$ de construir grandes caixas segregadoras dos itens básicos que compõem as maquetes.

Seguindo o princípio dos 3Rs, com a ideia da redução, do reuso e da reciclagem de materiais, um modelo específico de gestão de resíduos produzidos pelo ARQ foi gradativamente desenvolvido e implantado. Em 2010, a coordenação do Projeto 3R lançou um concurso para a concepção de um contentor a ser construído com o máximo de material reciclável. Foi vencedor um contentor construído apenas com garrafas PETs, que sofreu adaptações para atender ao acondicionamento dos materiais no interior do ARQ. Consta no relatório UFSC (2013) que, em razão das condições facilitadoras oferecidas pelas oficinas e o solidário apoio dos alunos da disciplina de Planejamento Ambiental Urbano, foi possível realizar a construção dos módulos de contentores da coleta seletiva.

O sistema completo do modelo idealizado pelo Projeto 3R foi inaugurado em 2012. No relatório UFSC (2013), bastante completo acerca do planejamento e da execução das atividades, constam recomendações sobre os cuidados a serem tomados pela administração do ARQ para a manutenção e continuidade dos trabalhos. Ao final de 2012, o coordenador do Projeto 3R afastou-se do ARQ para formação no exterior, resultando na diminuição das atividades referentes à operacionalização do Projeto 3R, considerando a sua intensiva dedicação para que as ações fossem executadas. 
Seguindo a trilha delineada, com a compreensão obtida no referencial teórico e a compilação dos dados coletados, foi feita a correlação dos conteúdos das falas dos entrevistados com os critérios de análise das três categorias selecionadas, à procura por constatações ou ausências de indicativos da gestão do Projeto 3R dentro da noção de gestão social. Com base em significativos fragmentos de falas e percepções de significados pelos pesquisadores, similar a um processo dialético, adveio a consecução da análise do conteúdo, explicitada a seguir.

Indicadores da categoria denominada de processo de discussão, como canais de difusão e a qualidade da informação, foram buscados por meio do questionamento quanto ao meio pelo qual o sujeito da pesquisa tomou conhecimento do Projeto 3R e se tinha clareza acerca dos objetivos deste.

Quanto à divulgação, os entrevistados informaram terem tomado conhecimento do Projeto 3R por meio do coordenador. Apenas um sujeito da pesquisa respondeu ter sido convidado a participar por outro integrante da equipe. Sobre ter conhecimento dos objetivos, 16 sujeitos demonstraram entendimento parcial dos objetivos específicos do Projeto 3R (UFSC, 2013). Os entrevistados referiram-se aos objetivos como sendo a separação interna e o reaproveitamento de resíduos no âmbito do ARQ. Um aluno respondeu que o Projeto 3R não foi apresentado em detalhes e que sua participação foi nas oficinas para a construção das lixeiras internas, deixando em aberto a resposta sobre os objetivos. No entanto, este sujeito de pesquisa, no decorrer da conversa, demonstrou também ter entendido, minimamente, sobre a ideia de separação e reaproveitamento de resíduos internamente ao ARQ.

Dos cinco sujeitos que constituem o grupo de apoiadores internos, apenas dois tiveram o entendimento um pouco mais ampliado em relação ao projeto. Para eles, além da separação e do reaproveitamento de resíduos sólidos no âmbito do ARQ e da implementação de uma educação ambiental, o Projeto 3R também foi pensado para servir como piloto para demais setores da UFSC. Um dos apoiadores externos não soube responder sobre quais seriam os objetivos do Projeto 3R. E para outro apoiador externo o objetivo do projeto seria, simplesmente, o atendimento da legislação que preconiza a separação de resíduos por órgãos públicos. De um modo geral, embora os objetivos não tenham ficado claros em sua totalidade, a ideia central da separação e do reaproveitamento de resíduos ficou registrada.

A existência de indicadores a respeito da transversalidade e da pluralidade, no processo de criação e operacionalização, ficou bastante clara por meio da análise dos relatórios do Projeto $3 \mathrm{R}$ (UFSC, 2013). Essa constatação motivou a busca por informações sobre a participação de outros setores internos e externos à UFSC, por meio das entrevistas e por visitas a locais de interesse. A interação do processo de implementação do Projeto 3R com a administração do ARQ caracteriza a transversalidade com uma instância local (Tenório et al., 2008). Essa característica ficou demonstrada na fala do representante institucional (E13) no âmbito do ARQ, quando se referiu ao seu trabalho de convencimento dos funcionários para a mudança na rotina de recolhimento dos resíduos: "Tendo consciência sobre a importância do projeto, procuramos levar isso adiante para, realmente, levar o lixo lá fora da forma como deveria ser. Tentamos apoiar o projeto considerando que é uma atividade importante para o ambiente."

Também foram encontrados indicadores do processo de discussão, que apontam para a atuação da gestão do Projeto 3R com um bom aproveitamento, em especial, dos espaços transversais criados por meio da participação de alunos. Esses espaços podem ser percebidos no seguinte fragmento da colocação do entrevistado (E14),

Na verdade, na arquitetura, como consciência social, de como a gente pode resolver, a forma é integrada à sociedade e ao espaço, você mudando o espaço, você naturalmente, reorganiza o social, o ambiente se transforma. Então é isso que a gente está tentando fazer com o pessoal. Olha aqueles lixeiros que lindo! Vamos utilizar, transformar e atrair.

A percepção desse entrevistado confirma o que Ramos (1981) aborda sobre o tratamento do espaço de acordo com a constituição dos sistemas sociais como um meio de estimular a atmosfera psicológica apropriada a seus objetivos específicos. O potencial criativo dos atores envolvidos, 
bastante valorizado nos meios acadêmico e profissional da área de arquitetura, uma vez colocado em pauta, não apenas reduziu resistências, mas fortaleceu o processo de implementação do Projeto 3R, para que o mesmo tivesse êxito.

Quanto ao processo de criação, ficou claro que o Projeto 3R foi desenvolvido a partir do Gipedu, tendo como concepção de base a ideia do trabalho interdisciplinar. Para um dos integrantes desse grupo de pesquisa, em meio aos trabalhos, houve uma socialização desde a formulação do projeto (E5). Para outro integrante do Gipedu, o Projeto 3R foi um dos projetos nascidos na disciplina Planejamento Urbano e Ambiental (E3). Segundo esse entrevistado, outros projetos foram desenvolvidos, a partir desta disciplina, como os projetos do Parque do Rio Vermelho e da Barra da Lagoa, sendo que o Projeto 3R é o mais recente. De acordo com o coordenador do Projeto 3R (E12),

A disciplina optativa é um projeto do grupo de pesquisa, além do projeto do Rio Vermelho, o Estação das Bicicletas, o Projeto 3R, o quarto projeto é a disciplina optativa. Então, ela foi a nossa base, onde nós desenvolvemos essa ideia da integração entre pesquisa, extensão e ensino.

Indicativos da categoria pluralismo ficam assim evidenciados com base nestes depoimentos, mas a participação de diferentes atores com seus pontos de vista, no desenvolvimento do Projeto 3R, fica mais clara com a seguinte colocação do coordenador: "[...]a ideia é pensar os resíduos do ponto de vista da arquitetura, mas buscando a complementaridade nas demais áreas que são afins, que são, vamos dizer assim, as interfaces do problema e da solução, basicamente isso é que nos moveu." (E12).

As falas dos entrevistados foram evasivas acerca do critério da participação de diferentes atores, como associações, organizações e cidadãos não organizados no processo de tomada de decisão das ações relativas à criação e à operacionalização do Projeto 3R. Isso não proporcionou clareza quanto a participação de outros atores no processo. Contudo, na operacionalização do Projeto 3R, foi identificado como indicador desse critério a participação efetiva da Companhia de Melhoramentos da Capital (Comcap) nas discussões sobre a melhor forma de disposição pelo ARQ dos resíduos para a coleta externa. A Comcap é uma entidade da Prefeitura do Município Florianópolis. De acordo com seu representante (E10), a empresa, ao participar das discussões em reuniões no próprio espaço físico do $\mathrm{ARQ}$, contribuiu com a sua experiência no serviço de coleta de resíduos no município de Florianópolis. A busca pela coordenação do Projeto 3R por este apoio externo, que resultou na participação efetiva da Comcap, demonstra responsabilidade e comprometimento na esfera pública de ambas as partes. Na implementação poder-se-iam, ainda, encontrar indicadores do pluralismo no intenso trabalho de troca de experiências e na busca da originalidade de alunos envolvidos no processo deliberativo para executar as ações trazidas pelo coordenador (E1; E14).

Quanto a um intercâmbio interno de experiências entre setores da UFSC, identificou-se um lapso de participação. O setor da Prefeitura Universitária, citada como um apoiador interno no relatório UFSC (2013) e selecionada para a amostragem, pode ser citado como exemplo. Seu representante, ao ser procurado, preferiu não formalizar uma entrevista sob a justificativa de não ter participado efetivamente do Projeto 3R. No entanto, confirmou ter contribuído com o empréstimo de ferramentas e equipamentos, os quais eram apenas deixados no $\mathrm{ARQ}$, afirmando não ter se envolvido diretamente, pois, para ele, tratava-se de um projeto pessoal de um professor do ARQ. Considerando esta colocação, não houve, de fato, um comprometimento institucional com o Projeto $3 R$, que foi visto como uma iniciativa pontual em um determinado espaço físico da universidade.

$\mathrm{O}$ alcance do bem comum pode ser traduzido no contexto desta pesquisa por apropriadas soluções para a gestão dos resíduos sólidos produzidos pela ação individual e coletiva do cidadão. Considerando ainda que a implementação do Projeto 3R aconteceu no espaço público da universidade, o bem comum pode, também, ser visualizado na formação acadêmica e cidadã dos estudantes envolvidos. Deste ponto de vista, é notório, na visão da maioria dos entrevistados, que os 
objetivos do Projeto 3R foram atingidos: seja num formato físico propriamente, quando por determinado tempo, de fato, o projeto colaborou para a redução da geração de resíduos em função do reuso dos materiais resultantes do desmonte de maquetes, ao final do semestre, para a construção de novas maquetes no semestre seguinte; ou, no âmbito da conscientização sobre a problemática ambiental e da responsabilização individual e coletiva sobre as possíveis soluções.

$\mathrm{Na}$ fala de alguns entrevistados, mesmo aqueles que não tiveram uma efetiva participação em discussões, é possível encontrar uma clareza acerca da problemática ambiental e da responsabilidade cidadã na busca por soluções. Segundo um dos sujeitos, constava no planejamento do Projeto 3R o envolvimento de indivíduos na execução das ações. Essa meta, segundo ele, foi cumprida. Referindo-se ao trabalho desempenhado pelo coordenador do Projeto 3R, conta esse entrevistado que:

[...] num sábado, ele estava com todos os estudantes lá, colocando a mão na massa, produzindo. Ele me chamou pra ver o que estava sendo feito, como é que estava sendo feito, no que diz respeito minha parte se estava sendo atendido as considerações que eu tinha feito. Então ele sempre buscava visando o objetivo final, a participação de cada um com o que estava sendo desenvolvido. (E7).

Essa consciência sobre o comprometimento com o alcance do bem comum, evidenciada na fala acima, também fica explicita em colocações de docentes envolvidos com a criação do Projeto 3R. Estes, quando entrevistados, lembram de questionamentos de alunos e representantes da comunidade quanto à contradição entre o ensino e a prática na universidade (E3, E5). No depoimento a seguir, o sujeito de pesquisa evidencia o questionamento sobre a efetividade da prática do ensino:

Às vezes, eu e os meus colegas, trabalhando com as comunidades ou mesmo com os alunos, somos perguntados: "mas professor, qual é a aplicação que se faz dessa teoria, dessa abordagem, de que maneira vocês estão aplicando aquilo que vocês ensinam?". Não era tão comum acontecer, mas acontecia, as comunidades eram críticas, porque nosso trabalho não tinha uma aplicação imediata na realidade, havia muita discussão, muita comunicação, em termos de educação ambiental, mas pouca ação direta na realidade, transformadora. (E12).

A entrevista desse sujeito, mostra que o comprometimento com o bem comum, também surgiu do questionamento realizado por alunos e pela comunidade sobre a aplicação do que era pesquisado e ensinado em sala de aula. Dessa forma, ficou evidente que o bem comum foi gerado por meio de uma prática de extensão universitária, proporcionada pelas atividades realizadas pelo Projeto 3R.

Realizada a análise das categorias e dos critérios selecionados para a pesquisa, expostas na figura 2, é possível apresentar uma síntese dos resultados. Essa síntese, demonstrada na figura 3, possibilita que seja visualizada a abordagem teórica da gestão social, por meio das categorias de análise elencadas como diretrizes desta pesquisa, e os respectivos indicativos obtidos pela análise do conteúdo das entrevistas semiestruturadas. 


\begin{tabular}{|c|c|c|c|}
\hline Categoria & $\begin{array}{c}\text { Descrição da } \\
\text { categoria }\end{array}$ & Critérios & Indicativos \\
\hline \multirow{8}{*}{$\begin{array}{l}\text { Processo de } \\
\text { discussão }\end{array}$} & \multirow{8}{*}{$\begin{array}{lr}\text { Discussão } & \text { de } \\
\text { problemas por meio da } \\
\text { autoridade negociada } \\
\text { na esfera pública. } \\
\text { Pressupõe igualdade } \\
\text { de direitos e é } \\
\text { entendido como um } \\
\text { espaço intersubjetivo e } \\
\text { comunicativo rue } \\
\text { possibilita } \\
\text { entendimento } \\
\text { atores do } \\
\text { envolvidos. }\end{array}$} & $\begin{array}{l}\text { Canais de difusão: existência e } \\
\text { utilização de canais adequados ao } \\
\text { acesso à informação para a } \\
\text { mobilização dos potenciais } \\
\text { participantes. }\end{array}$ & $\begin{array}{l}\text { O principal meio de difusão foi a } \\
\text { divulgação e ação do próprio } \\
\text { coordenador do projeto. }\end{array}$ \\
\hline & & $\begin{array}{l}\text { Qualidade da informação: } \\
\text { diversidade, clareza e utilidade da } \\
\text { informação proporcionada aos } \\
\text { atores envolvidos. }\end{array}$ & $\begin{array}{l}\text { A ideia central do } 3 \mathrm{R} \text { ficou clara. } \\
\text { Informações sobre a participação } \\
\text { de outros setores ficaram } \\
\text { centralizadas no coordenador. }\end{array}$ \\
\hline & & $\begin{array}{l}\text { Espaços de transversalidade: } \\
\text { espaços que atravessam setores } \\
\text { com o intuito de integrar diferentes } \\
\text { pontos de vista. }\end{array}$ & $\begin{array}{l}\text { Na criação do Projeto } 3 \mathrm{R} \text {, a partir } \\
\text { da interdisciplinaridade dos atores } \\
\text { envolvidos e nas ações de } \\
\text { execução com os alunos. }\end{array}$ \\
\hline & & $\begin{array}{l}\text { Pluralidade do grupo promotor: } \\
\text { compartilhamento da liderança a } \\
\text { fim de reunir diferentes potenciais } \\
\text { atores. }\end{array}$ & $\begin{array}{l}\text { A condução dos trabalhos foi } \\
\text { concentrada no coordenador. }\end{array}$ \\
\hline & & $\begin{array}{l}\text { Órgãos existentes: uso de órgãos e } \\
\text { estruturas já existentes evitando a } \\
\text { duplicação das estruturas. }\end{array}$ & $\begin{array}{l}\text { Utilização parcial de setores e } \\
\text { estruturas da UFSC. }\end{array}$ \\
\hline & & $\begin{array}{l}\text { Órgãos de acompanhamento: } \\
\text { existência de um órgão que faça o } \\
\text { acompanhamento de todo o } \\
\text { processo, desde sua elaboração até } \\
\text { a implementação, garantindo a } \\
\text { coerência e fidelidade ao que foi } \\
\text { deliberado de forma participativa. }\end{array}$ & $\begin{array}{l}\text { Acompanhamento pelo próprio } \\
\text { coordenador. }\end{array}$ \\
\hline & & $\begin{array}{l}\text { Relação com outros processos } \\
\text { participativos: interação com } \\
\text { outros sistemas participativos já } \\
\text { existentes na região. }\end{array}$ & Não houve. \\
\hline & & $\begin{array}{l}\text { Abertura dos espaços de decisão: } \\
\text { processos, mecanismos, instituições } \\
\text { que favorecem a articulação dos } \\
\text { interesses dos cidadãos ou dos } \\
\text { grupos, dando uma chance igual a } \\
\text { todos de participação na tomada de } \\
\text { decisão. }\end{array}$ & $\begin{array}{l}\text { Ocorreu a abertura para processos } \\
\text { criativos de alunos para a execução } \\
\text { de ações no âmbito operacional. }\end{array}$ \\
\hline \multirow[t]{2}{*}{ Pluralismo } & \multirow{2}{*}{$\begin{array}{l}\text { Multiplicidade de } \\
\text { atores (poder público, } \\
\text { mercado e sociedade } \\
\text { civil) que, a partir de } \\
\text { seus diferentes pontos } \\
\text { de vista, estão } \\
\text { envolvidos no } \\
\text { processo de tomada de } \\
\text { decisão nas políticas } \\
\text { públicas. }\end{array}$} & 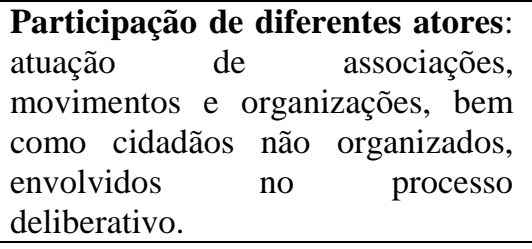 & $\begin{array}{l}\text { Houve a participação de diferentes } \\
\text { atores no processo de criação. } \\
\text { Atuação da Comcap e de alunos na } \\
\text { operacionalização. }\end{array}$ \\
\hline & & $\begin{array}{l}\text { Perfil dos atores: características } \\
\text { dos atores em relação as suas } \\
\text { experiências em processos } \\
\text { democráticos de participação. }\end{array}$ & Não encontrado. \\
\hline \multirow[b]{2}{*}{$\begin{array}{l}\text { Bem } \\
\text { comum }\end{array}$} & \multirow[b]{2}{*}{$\begin{array}{l}\text { Bem-estar social } \\
\text { alcançado por meio da } \\
\text { prática republicana. }\end{array}$} & $\begin{array}{l}\text { Objetivos alcançados: relação } \\
\text { entre os objetivos planejados e os } \\
\text { realizados. }\end{array}$ & $\begin{array}{l}\text { Os objetivos foram alcançados, em } \\
\text { especial quanto à conscientização. }\end{array}$ \\
\hline & & $\begin{array}{l}\text { Aprovação cidadã dos resultados: } \\
\text { avaliação positiva dos atores sobre } \\
\text { os resultados alcançados. }\end{array}$ & $\begin{array}{l}\text { Teve a aprovação cidadã. Ressalta- } \\
\text { se que os atores demonstraram, } \\
\text { cada qual à sua maneira, uma } \\
\text { responsabilização pelo bem } \\
\text { comum. }\end{array}$ \\
\hline
\end{tabular}

Figura 3: Categorias e respectivos critérios selecionadas para a pesquisa

Fonte: Adaptado, pelos autores, a partir de Tenório et al (2008) 
Na figura 3, é possível observar que para todas as categorias escolhidas para a pesquisa, como características da gestão social, foram encontradas informações que confirmam sua existência na operacionalização do Projeto 3R. Em relação aos critérios dessas categorias, foram identificados indicativos correspondentes a eles. A exceção foram os critérios de relações com outros processos participativos e do perfil dos atores, os quais não foram encontradas evidências concretas por meio da pesquisa.

Por fim, cabe destacar que a principal ação para a operacionalização ficou caracterizada na inserção a cada semestre, a partir de 2006, do Projeto 3R no conteúdo programático da disciplina Planejamento Ambiental Urbano (E12) e de outras disciplinas. Assim, alunos foram convidados a participar da execução de ações, como a construção de lixeiras internas (E2; E16). A ideia da interdisciplinaridade que envolveu a criação do Projeto $3 \mathrm{R}$ e a prática participativa para a sua operacionalização traduzem aspectos da abordagem teórica da gestão social, como apontou a análise dos dados desta pesquisa. A participação e o envolvimento de sujeitos apontam para a emancipação, em especial, de alunos convocados a exercer suas potencialidades criativas no planejamento e na execução de ações que dessem vida ao Projeto 3R. No entanto, percebeu-se um grande potencial inexplorado entres os participantes.

\section{CONSIDERAÇÕES FINAIS}

O bem público é um atributo da universidade como um espaço público (Habermas, 1995) e entendido como uma ação social com potencial para fomentar uma organização natural de sujeitos ou de um fazer que propicie um espaço comum a todos. Ele também pode ser considerado uma ação social não orquestrada (Shoumer; Boullosa, 2011) no sentido de promover a autonomia humana.

Formar a cidadania de acordo com tais prerrogativas leva exatamente ao que se faz necessário para uma autêntica gestão social e ambiental. Dessa forma, este trabalho procurou realizar uma pesquisa com base na gestão social e ambiental, a partir de um estudo de caso no contexto de um ambiente universitário, em certa medida corrompido pela influência direta do mercado, o qual, de acordo com Ramos (1981), tem modelado a mente dos cidadãos.

No desenvolvimento deste estudo, além de serem tratadas questões relativas à sua legitimidade e ao seu caráter institucional, o espaço universitário foi visto a partir de sua inerente complexidade. Essa configuração oportuniza que visões, ideias e percepções individuais e do conjunto, interajam, proporcionando ganhos para o desenvolvimento humano e profissional para servidores docentes e técnicos administrativos da universidade.

Pensar a gestão pública da universidade a partir dessas perspectivas e como um espaço legítimo para a formação da cidadania, indica que há a necessidade de realizar maiores estudos em gestão ambiental sobre o prisma da gestão social. Esta observação faz sentido, uma vez que, entre outros aspectos, a gestão social preconiza a interatividade, a intersubjetividade e a cooperação entre cidadãos/sujeitos como vias de acesso à realização do bem comum, do melhor para todos, oportunizando novas formas de relacionamento, não apenas do homem com a natureza, mas dos homens entre si. Tal configuração assemelha-se à visão sistêmica de funcionamento de um conjunto, de um todo.

Foi procurando perceber o ambiente pesquisado como um sistema aberto, a partir do arcabouço teórico da gestão social e ambiental, que o estudo foi desenvolvido, especialmente na etapa de coleta de dados, quando o referencial teórico acerca de sistemas complexos já havia sido elucidado. A partir desse olhar, percepções tomaram forma. Muito embora se faça necessário o aprofundamento da pesquisa, é possível considerar uma pressuposição quanto à aplicabilidade da abordagem da gestão social no âmbito da gestão ambiental, sob a ótica de um sistema complexo.

$\mathrm{Na}$ abordagem teórica da gestão social, ao tratar de relações sociais considerando aspectos inerentes a processos de discussão e dialogicidade, por exemplo, a intersubjetividade humana, com suas interfaces e diferentes formas de interagir, garante-se a participação efetiva de sujeitos. Isso seria uma abertura de espaços transversais, a partir de processos de discussão, proporcionando 
possibilidades e novas concepções surgidas desde de trocas de energia e saberes inatos de um sistema aberto.

A prática de tais conceitos abre espaço justamente para o reconhecimento de atributos de um ambiente sistêmico, onde a interdependência entre potencialidades pode representar possibilidades para a reconfiguração do atual estado de alienação imposto pela hegemonia modeladora da sociedade contemporânea, o que repercutirá diretamente numa forma diferenciada de pensar a gestão ambiental. A pesquisa aqui desenvolvida, de forma similar a um sistema aberto, encontrou na gestão do Projeto 3R um campo de troca e interação entre potencialidades humanas. Nas etapas de coleta e análise dos dados, foi facilmente perceptível, por exemplo, o potencial de sujeitos ativos para o desenvolvimento de um trabalho coletivo caracterizado pela participação deliberativa.

De acordo com os dados coletados nas entrevistas, tais potenciais foram mobilizados em razão da percepção da importância dos objetivos propostos e da liberdade de ação proporcionada pela coordenação do Projeto 3R. Na prática, para que um sistema funcione de acordo com a sua inerente complexidade, basta que o ambiente seja propício a tal. O Projeto 3R demonstrou claramente esta prerrogativa, com a abertura oportuna para o desenvolvimento do pensar e da criatividade dos alunos participantes no processo de sua operacionalização.

Foi notado, ainda, que o ambiente proporcionado nas entrevistas no formato semiestruturado para a coleta de dados também propiciou momentos de reflexão para alguns sujeitos da pesquisa. Ao serem colocadas questões pertinentes ao tema da pesquisa, houve uma pausa para o pensar e o elaborar suas respostas. Esse momento parece ter aberto um campo para a reflexão. É factível que as correlações entre a abordagem da gestão social e sistemas abertos possam ser levadas à gestão ambiental e ao ambiente universitário, onde a inerente complexidade tem sido vista também como oportuna para o desvendar de soluções multifacetadas. Considerando, porém, que as inferências colocadas neste capítulo caracterizam apenas um ensaio a partir de percepções e breve análise empírica/conceitual, sugere-se a implementação de pesquisas a fim de confirmar tais alegações.

Para futuros trabalhos, sugere-se ainda o aprofundamento de pesquisa em caráter institucional na área da interdisciplinaridade, cuja construção acadêmica vem ganhando adeptos ao longo das últimas décadas para atender as demandas da área ambiental. Leff (2001), porém, alerta para a impossibilidade de se estabelecer uma metodologia que dê conta de respeitar o teor de diferentes abordagens teóricas, devendo-se ter o cuidado de considerar as peculiaridades e a essência de cada uma delas. São dificuldades inerentes ao processo de mudança de paradigma.

Também deve ser considerado que trabalhos desenvolvidos num formato interdisciplinar, onde é premente a troca, a confluência de ideias e a aproximação de conhecimentos oportunizam o desenvolvimento de capacidades que poderão contribuir com novas percepções. Esses trabalhos, como é o Projeto 3R, abrem espaço para a implementação dos pressupostos da gestão social.

É na esteira da abordagem teórica conceitual da gestão social e do pensamento sistêmico que parecem ter possibilidades de construção de uma nova configuração institucional da universidade. E por consequência, a gestão ambiental estaria também amparada. Essa prática poderá repercutir positivamente na formação de estudantes que pela universidade passam. Poder-se-ia, ainda, esperar a melhoria das relações com prestadores de serviços que com ela convivem, dando-lhes exemplo de autêntica formadora de opinião. É dessa forma, numa complexa teia de interligações e interfaces, que a sociedade, que espera da universidade atitudes de um educador/formador como legítima produtora do bem comum, estaria, quem sabe, sendo atendida.

\section{REFERÊNCIAS}

Bardin, L. (1977) Análise de conteúdo. São Paulo: Edições 70.

Cabral, E. H. S. (2006) Espaço público e controle para a gestão social no terceiro setor. Serviço Social e Sociedade, 86(1), 30-55. 
Cançado, A. C., Pereira, J. R., \& Tenório, F. G. (2015) Gestão social: epistemologia de um paradigma (2a ed.). Curitiba: Editora CRV.

Carson, R. L. (1969) Primavera silenciosa. São Paulo: Melhoramentos.

Castellà, C., \& Jorba, L. (2005) Evaluación de las experiências participativas em la gestión local de Cataluña: potencialidades y amenazas. Gestión y Análisis de Políticas Públicas, 32(1), 79-98.

Chauí, M. S. (2003) A universidade pública sob nova perspectiva. Revista Brasileira de Educação, 22(3), 5-15.

Dowbor, L. (1999) Tendências da gestão social. Saúde e Sociedade, 1(8), 3-16.

Fischer, T. (2012) Gestão social do desenvolvimento de territórios. Revista Psicologia, 22(1), 113119.

Godoy, A. S. (2012) Estudo de qualitativo. In C. K. Godoi, R. Bandeira-de-Melo, \& A. B. Silva, Pesquisa qualitativa em estudos organizacionais: paradigmas, estratégias e métodos (2a ed.), 115146. São Paulo: Saraiva.

Habermas, J. (1995) Três modelos normativos de democracia. Lua nova - revista de cultura e política, 36, 39-53.

Habermas, J. (2003) Mudança estrutural da esfera pública. Rio de Janeio: Tempo Brasileiro.

Hirschman, A. O. (2002) As paixões e os interesses: argumentos políticos a favor do capitalismo antes de seu triunfo. Rio de Janeiro: Record.

Jorba, L., Martí, J., \& Parés, M. (2007) La qualitat em la participació: orientacion per l'avalució participada. Barcelona: Fundació Jaume Bofill.

Justen, C. E., \& Neto, L. M. (2012). Do economicismo à dialogicidade: as contribuições do paradigma da ecologia profunda e da noção de gestão social para a temática da sustentabilidade empresarial. Cadernos Ebape, 10(3), 736-750.

Layrargues, P. P. (1998) A cortina de fumaça: o discurso empresarial verde e a ideologia da racionalidade econômica. São Paulo: Annablume.

Leff, E. (2001) Saber ambiental: sustentabilidade, racionalidade, complexidade e poder. Petrópolis: Vozes.

Lievegoed, B. (1994) Fases da vida: crises e desenvolvimento da individualidade. São Paulo: Antropofásica.

Meadows, D. H., Meadows, D. L., \& Randers, J. (1972) Limites do crescimento: um relatório para o projeto Clube de Roma sobre o dilema da humanidade. São Paulo: Perspectiva.

Morin, E. (2010) Meu caminho: entrevistas com Djénane Kareh Tager. Rio de Janeiro: Bertrand do Brasil.

Minayo, M. C. S., \& Sanches, O. (1993) Quantitativo-qualitativo: oposição ou complementaridade. Cadernos de saúde pública, 9(3), 239-262.

Paes de Paula, A. P. (2005) Por uma nova gestão pública: limites e potencialidades da experiência contemporânea. Rio de Janeiro: Editora FGV.

Parés, M., \& Castellà, C. (2008) Criteris, metodologies i reflexions entorn l'avaluació de la participació ciutadana. Barcelona: Epsu/Igop/UAB.

Peres, Jr. \& Pereira, J. R. (2014) Abordagens teóricas da gestão social: uma análise de citações exploratórias. Cadernos Ebape, 12(2), 221-236. 
Ramos, A. G. (1981) A nova ciência das organizações: uma reconceituação da riqueza das nações. Rio de Janeiro: Editora da Fundação Getúlio Vargas.

Ramos, A. G. (1996) A redução sociológica: introdução ao estudo da razão sociológica (3a ed.). Rio de Janeiro: Editora UFRJ.

Richardson, R. J. (2007) Pesquisa social: métodos e técnicas (3a ed.). São Paulo: Atlas.

Sachs, I. (1986) Ecodesenvolvimento: crescer sem destruir. São Paulo: Revista dos Tribunais.

Sachs, I. (2009) Caminhos para um desenvolvimento sustentável. Rio de Janeiro: Gramond.

Santos, B. S. (2011) A universidade no século XXI: para uma reforma democrática e emancipatória da universidade. São Paulo: Cortez.

Shommer, P. C., \& Boullosa, R. F. (2011) Fronteiras de aprendizagem da gestão social. In P. C. Shommer, \& R. F. Boullosa. Gestão social como caminho para a redefinição da esfera pública, 914. Florianópolis: Udesc.

Steiner, R. (2011) Os pontos centrais da questão social: aspectos econômicos, político-jurídicos e espirituais da vida em sociedade. São Paulo: Antropofásica.

Tenório. F. G. (2008) (Re) Visitando o conceito de gestão social. In J. T. Silva Jr., R. T. Mâish, A. C. Cançado, \& P. C. Schommer. Práticas em debate, teorias em construção. Fortaleza: Imprensa Universitária.

Tenório, F. G., Villela, L. E., Dias, A. F., Gurjão, F. V., Porto, E., \& Vianna, B. (2008) Critérios para a avaliação de processos decisórios participativos deliberativos na implementação de políticas públicas. Anais Encontro de Administração Pública e Governança. Salvador, Novembro, 3.

Universidade Federal de Santa Catarina - UFSC. (2013) Projeto 3Rs ARQ-UFSC. Florianópolis: UFSC.

Vergara, S. C. (2010) Projetos e relatórios de pesquisa em administração. São Paulo: Atlas.

Villela, L. E. (2012) Escopo metodológico. In F. G. Tenório. Cidadania e desenvolvimento local: critérios e análise, 35-46. Rio de Janeiro: Editora FGV.

Data da submissão: 10/05/2016

Data de aceite: $26 / 01 / 2017$ 